\title{
A GARÇA EM PLENO VOO: ZONAS DE CONTATO COMUNICATIVO DO POLO INDUSTRIAL DE MANAUS
}

\section{THE HERON IN FULL FLIGHT: COMMUNICATIVE CONTACT ZONES OF THE MANAUS INDUSTRIAL POLE}

\section{LA GARZA EN PLENO VUELO: ZONAS DE CONTACTO COMUNICATIVO DEL POLO INDUSTRIAL DE MANAUS}

\author{
Edilson Santos de Oliveira Duarte ${ }^{1}$ \\ Wilson de Souza Nogueira²
}

\begin{abstract}
Resumo: A rede comunicacional do Polo Industrial de Manaus (PIM) encobre a real situação de insucesso social, tecnológico e ecológico do modelo. Chegamos a esse entendimento depois de investigar a ecossistêmica rede de articulação imaginária entre o símbolo visual do PIM (SV-PIM), a garça em pleno voo, com os públicos dos meios utilizados pela Suframa, a autarquia administradora dos incentivos fiscais do modelo. Se por um lado as sucessivas prorrogações do PIM revelam o seu fracasso como elemento alavancador de desenvolvimento regional, por outro a mídia esconde por trás da imagem de sucesso do modelo veiculada pelo SV-PIM que reafirma o conjunto de imaginários formado a partir da literatura dos primeiros viajantes, passando pelos religiosos, cientistas até aos inventados recentemente pelas tecnologias do imaginário.
\end{abstract}

Palavras-chave: Ecossistema comunicacional, símbolo visual, Imaginário, linguagem estética, Polo industrial de Manaus.

\begin{abstract}
The communication network of the Manaus Industrial Pole (PIM) covers the real situation of social, ecological and technological failure of the model. We come to this understanding after investigating the network ecosystem of imaginary articulation between the visual symbol of the PIM (SV-PIM), crane in full flight, with the audiences of the means used by Suframa, the city administrator of tax incentives. If on the one hand the successive extensions of the PIM reveal your failure as a leverage element of regional development by other media hide behind the successful image of the model conveyed by SV-PIM that reaffirms the imaginary set formed from the literature of the first travelers through the religious, scientists to the recently invented by imaginary technologies.
\end{abstract}

Keywords: communicational ecosystem, visual symbol, imaginary, aesthetic language, Industrial Pole of Manaus.

Resumen: La red comunicacional del Polo Industrial de Manaus (PIM) encubre la real situación de fracaso social, tecnológico y ecológico del modelo. Llegamos a ese entendimiento después de investigar la ecosistémica red de articulación imaginaria entre el

\footnotetext{
${ }^{1}$ Mestre em Ciências da Comunicação pela Universidade Federal do Amazonas (2016). Professor do Instituto Federal de Educação, Ciência e Tecnologia do Amazonas.

2 Doutor em Sociedade e Cultura na Amazônia pela Universidade Federal do Amazonas, Brasil (2013). Pesquisador em pós-doutoramento no PPGCCOM da Universidade Federal do Amazonas.
}

Fronteiras: Revista de História | Dourados, MS |v. 19 | n. 33 |p. 109 - 130 | Jan. / Jun. 2017 
símbolo visual del PIM (SV-PIM), la garza en pleno vuelo, con los públicos de los medios utilizados por Suframa, la autarquía administradora de los incentivos fiscales del modelo. Si por un lado las sucesivas prórrogación del PIM revelan su fracaso como elemento alavancador de desarrollo regional, por otro los medios esconden detrás de la imagen de éxito del modelo vehiculada por el SV-PIM que reafirma el conjunto de imaginarios formado a partir de la literatura de los libros. Los primeros viajeros, pasando por los religiosos, científicos hasta los inventados recientemente por las tecnologías del imaginario.

Palabras clave: Ecosistema comunicacional, símbolo visual, Imaginario, lenguaje estético, Polo industrial de Manaus.

\section{Introdução}

Através da perspectiva dos ecossistemas comunicacionais foi possível compreender que os sistemas socioculturais dominantes na sustentação do Polo Industrial de Manaus (PIM) se articulam, permanentemente, escamoteando as contrapartidas sociais que não cumprem com as populações locais/regionais. Assim, escondem o desvirtuamento do modelo de desenvolvimento econômico que prometia desde a eliminação da distância entre os níveis de riquezas gerados nos estados do Sul e Sudeste e os Estados do Norte até a manutenção da soberania do Brasil sobre a Amazônia. Chegamos a esse entendimento por meio do estudo da trajetória do Símbolo Visual do PIM (SV-PIM), a Garça em pleno voo (Figura 1).

Este estudo foi desenvolvido no âmbito da linha "Linguagens, representações e estéticas comunicacionais". Vale salientar, todavia, que essa perspectiva epistemológica entrelaça as mais diversas áreas do conhecimento em busca da elaboração de novos saberes. Os ecossistemas comunicacionais reconhecem que a comunicação não se realiza em si, de modo isolado, mas se relacionando com o seu entorno (PEREIRA, 2012). Nossa metodologia, portanto, consistiu em levantamento bibliográfico e documental dos indicadores econômicos da Suframa, leis e emendas que deram origem ao modelo e lhe causaram mudanças ao longo do tempo, em entrevista ao criador da identidade visual (Reginaldo Lima), na análise do discurso oficial implícito na selagem dos produtos made in PIM, Nas características semióticas do símbolo, como referências culturais presentes na imagem, aplicamos também o conceito de imaginário como conteúdo da mensagem veiculada de modo ecossistêmico pelos meios de comunicação, enquanto simulacro da cultura Amazônica. Partimos da hipótese de 
que se revelariam paradoxos entre a realidade e o que a comunicação oficial da Suframa apresenta.

Assim, recorremos a pensadores que interagem dialogicamente em favor da interdisciplinaridade e da transdisciplinaridade na pesquisa, desde o entrelaçamento nas fronteiras da semiótica (PEREIRA, 2012; MACHADO, 2007; SANTAELA, 2005), às relações complexas (MORIN, 2007), do imaginário (SARTRE 1971, DURAND, 1996; MAFFESOLI, 2014; SILVA, 2012; LOUREIRO, 2015; BENCHIMOL, 2009), à sociedade do espetáculo (DEBORD, 1967), da linguagem estética (DONDIS, 2007; ARHAIEN, 2006; FLUSSER, 1985) aos ecossistemas comunicacionais (MONTEIRO, 2011; PEREIRA, 2012). São autores que nos permitiram a compreensão do fenômeno pesquisado na sua relação complementar, antagônica e concorrente com as bioecossociodiversidades locais e globais.

Existe, portanto, na afirmação de sucesso econômico, social e ambiental do PIM, uma atmosfera imaginária disseminada pela mídia, situação que esconde a profundidade dos problemas relacionados a esse modelo de desenvolvimento regional. Exemplo que se confirma pelo crescente faturamento das empresas incentivadas e que mesmo assim não corresponde proporcionalmente - e em termos de contrapartida social - ao número de postos de trabalho. Ao mesmo tempo, esconde o desinteresse das empresas incentivadas em converter matérias-primas regionais em produtos de alta tecnologia associada aos ritmos da natureza e das culturas locais. A ideia de preservação defendida pelo PIM disfarça, certamente, o velho discurso do "santuário silvestre", como pontua Benchimol (2009).

\section{Zonas de contato}

A garça em pleno voo (figura 1) desempenha o papel de ligar e harmonizar sistemas que parecem díspares, mas que, no entanto, se tocam pela percepção do signo em ação a partir de um símbolo visual que almeja codificar a complexidade de relações dos sistemas que orbitam em torno do ecossistema comunicacional do PIM. É possível dizer que se revelou uma rede mediada entre as empresas, o meio ambiente amazônico e a sociedade/consumidores. Trata-se de uma relação ampla e complexa para qual o SV-PIM serve simultaneamente de codificador e tradutor. 


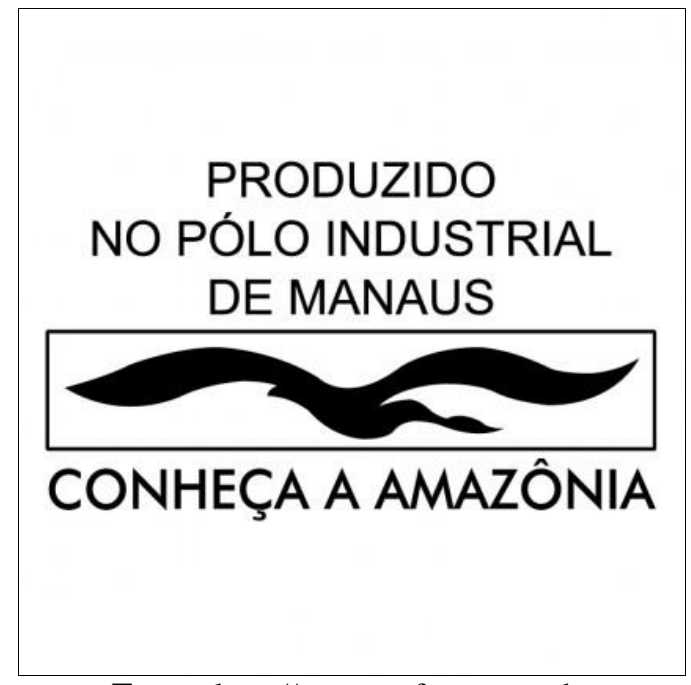

Fonte: http://www.suframa.gov.br

Elaborado para enlaçar produtor e consumidor, por meio de um conjunto de informações relacionadas ao ser humano, à natureza e à sociedade o SV-PIM é uma representação que se materializa na Garça em pleno voo (figura 1) e nas diversas ações mediadas pelo sistema midiático que objetivam propagar a ideia de conexão entre a indústria local as culturas e a natureza amazônica. A própria embalagem dos produtos made in PIM se constitui em uma tecnologia do imaginário a mediar a relação consumidor/produtor em qualquer lugar do planeta, e principalmente nos resistentes ao modelo. Uma vez que, a Zona Franca de Manaus (ZFM), hoje Polo Industrial de Manaus (PIM), desde a sua criação, em 1967, sempre foi considerada pela industrial nacional como agente predador. Os incentivos constituem uma renúncia fiscal para outros estados, uma espécie de "bolsa zona franca" (PEREIRA, 2006, p. 139). Daí se motiva a mudança de nome para Polo Industrial de Manaus (PIM), na tentativa de afastar-se da ideia de paraíso fiscal, conforme emenda aditiva à PEC n. ${ }^{\circ}$ 41 de 2003. Nas palavras de Botelho,

[...] a Zona Franca de Manaus passa a denominar-se polo industrial de Manaus, reservando-se seus benefícios tributários, suas finalidades inclusive a de promoção do desenvolvimento da Amazônia ocidental, e sua forma de administração com ajustes a nova legislação. (BOTELHO, 2006, p. 22) 
Nesse contexto, configura-se o símbolo como "catalisador" de significados, com abrangência sobre o sistema econômico, sobre o sistema de mídia e sobre o sistema biológico envolvidos no fenômeno sociocultural.

A conexão entre esses sistemas não é o contato material, mas o contato de ideias. O SV-PIM é a ponte para esta cognição, é o signo que passa a representar o ecossistema formado pelas relações complexas entre os sistemas envolvidos, uma vez que adquire interpretação de seu grupo social que o imaginário alimenta enquanto memória. Esse imaginário é representação de códigos. Pode-se dizer, então, que essa consciência a respeito da ação do símbolo como signo em semiose ratifica um processo comunicativo suportado por uma semiosfera, um ambiente onde diferentes narrativas simbólicas em relação constroem sistemas semióticos; é isso, em tese, que tornaria o SV-PIM tão presente no cotidiano amazonense e nacional.

Dentre essas narrativas temos o valor atribuído ao SV-PIM que se associa ao respaldo em razão dos incentivos fiscais, da qualidade por reunir sob seu emblema empresas de renome mundial e do capital social agora escudado sob a bandeira da ecologia, da economia sustentável e do nacionalismo que almeja integrar e preservar a Amazônia. Essa tendência à interpretação desse significado reforça e legitima o símbolo como nó de uma rede comunicativa entre sistemas econômico, biológico e midiático. Seguindo essa via interpretativa, o consumidor é persuadido a adotar a ideia de pertencimento a um ambiente comunicacional que gravita ao redor do PIM, graças à ação do SV-PIM, e se amalgama como imaginário coletivo das populações amazônicas.

\section{Forma e Conteúdo: o que se esconde por traz do que é mostrado}

Nesta construção de sentido, o SV-PIM encontra suporte por tecnologias diretamente responsáveis pela propagação de imaginário, como é o caso da publicidade que, com o patrocínio da Suframa, o expõe em diversos meios e, recentemente, com maior vigor e refinamento no discurso promocional. As novas abordagens em mídia eletrônica, internet e televisão, se constituem em tecnologias persuasivas para a construção desse conteúdo imaginário.

O PIM apresenta o meio ambiente amazônico como um "santuário ecológico" (BENCHIMOL, 2009, p. 508) e, como isso, apregoa o distanciamento do ser humano 
amazônico da natureza, ao mesmo tempo em que o atrela cada vez mais às suas mercadorias. Para Lemos (2013), esse fenômeno pode ser definido como a naturalização dos objetos e a objetivação da natureza. Nesse sentido, a medida do sucesso do PIM usa como "régua" a distância entre ser humano e natureza. Todavia, a espetacularização midiática desse ecossistema comunicacional prega o oposto: a harmonia entre ser humano, natureza, indústria e cultura amazônica. Assim, explora e amplifica então um imaginário amazônico, deslocandoo de forma espetacular para o âmbito da comunicação entre os sistemas, pois, para defender a ideia de importância do PIM, quanto a questões ambientais e sociais na Amazônia Ocidental, tende a obscurecer o paradoxo entre meio natural e produtos industrializados. Mais uma vez há oculto nessa articulação o desejo de expor-se como um símbolo de sustentabilidade, mas, conforme Brianezi (2013), o que ocorre, na realidade, é um oportuno deslocamento do discurso do progresso à modernização ecológica.

Isso embora transmita a ideia de integração indústria-natureza, a relação das empresas com a Amazônia não ultrapassa os muros de seus galpões. Inexiste realmente um compromisso legal ou moral em manter a floresta em pé, não agredi-la ou preservá-la. Lembremos que as empresas vêm para produzir bens que lhe tragam lucros; tudo que venham a fazer em beneficio local é por imposição legal das contrapartidas que lhe são exigidas pela concessão dos incentivos fiscais. Portanto, o que pesa nesta relação é o interesse econômico, inclusive por parte dos órgãos governamentais, até mesmo porque, conforme Laredo (2013, p. 171), “essas empresas contam com isenções de alguns impostos e alíquotas reduzidas em outros, e a parte de tributos que elas pagam torna o Amazonas o maior contribuinte do fisco federal de toda a região Norte". Logo, o PIM é um negócio que também interessa ao poder público pela arrecadação e pela reação sociocultural das empresas com a região.

Outro ponto de abordagem da comunicação do PIM aponta para a preservação florestal no Amazonas. Todavia, a área de atuação do PIM não se limita só ao Amazonas, fato que enfraquece o argumento de que $98 \%$ da floresta amazonense estão preservadas, uma vez que os índices de desflorestamento dos demais estados são escamoteados pela publicidade oficial. Segundo Laredo (2013, p. 28), no mesmo período da realização da pesquisa do INPE (Instituto Nacional de Pesquisas Espaciais) sobre desmatamento na região, outras áreas sob jurisdição da Suframa tiveram suas florestas reduzidas, como Rondônia em 20,4\% e Acre em 8,97\%. Além disso, a história econômica da região também torna sem efeito atribuir a preservação à industrialização local: 
Afirma-se que a reduzida degradação ambiental do estado do Amazonas se deve ao modelo de desenvolvimento da ZFM. Apenas em parte isto é verdade. $\mathrm{O}$ fato é que, a economia extrativa tradicional do Amazonas nunca depredou sensivelmente a natureza. Há mais de cem anos vimos gerando economia de nossas selvas e dos nossos rios, e aí está o nosso ecossistema quase intocável (LAREDO, 2013, p. 28).

No entanto, ainda que se obtenha o desenvolvimento industrial, considerando o ambiente em que nos encontramos, o PIM ainda será uma "economia de enclave" (BOTELHO, 2006, p. 184), porque a vocação da Amazônia tem como matéria-prima seus ecossistemas naturais e não a indústria da Zona Franca. O PIM na Amazônia é reflexo do desejo de posse que resultou num projeto apressado para a Amazônia e reflete um sentimento de cobiça sobre esta região. Prova disso, na opinião de Pereira (2006, p. 104), é que "a assembleia Nacional Constituinte de 1946 abriu espaço para o debate sobre a Amazônia enquanto responsabilidade do País, atentando para a questão da segurança nacional". No entanto, o PIM desenvolve-se em uma proporção que não se refletiu na qualidade de vida da população local. O SV-PIM com seu signo representa uma economia que tornou o ser humano amazônico refém de um único meio de subsistência, além de gerar conflito entre as economias internas. Conforme Pereira,

A dependência do Amazonas do modelo da ZFM, de um lado e, de outro, o significativo montante da renúncia fiscal que ela ocasiona ao restante do país, são ingredientes que desenham um permanente cenário de choques entre os interesses nacional e regional (PEREIRA, 2006, p. 20).

Ainda segundo Botelho (2006, p. 74), o fato de que "o espaço periférico, como o do projeto PIM, só produz com tecnologias de ponta em forma de segredo industrial representa, exemplarmente, o aspecto mercenário subjacente a questão”. Nesse sentido, o sucesso da indústria na Amazônia depende da transferência de tecnologia e recurso próprio para investimentos que propiciem a circulação econômica local em direção à hegemonia capitalconhecimento. Botelho (2006, p. 73) explica: “O capital, enquanto poupança própria, e tecnologia, baseada na configuração de massa crítica cientifica a serviço da própria nacionalidade". 
Fronteiras: Revista de História

A garça em pleno voo: zonas de contato comunicativo do Polo Industrial de Manaus Edilson Santos de Oliveira Duarte; Wilson de Souza Nogueria

\section{A recepção do SV-PIM}

O público alvo dessa mensagem é diversificado. Vai desde os consumidores até os produtores, os quais também são partes da mensagem e, assim, constituem um ecossistema comunicacional, mesmo porque a aura socioambiental e o imaginário Amazônico contagiam até os emissores da mensagem. Trata-se de uma questão em que "o programa afeta o programador" (FLUSSER, 1985) ou "da desconfiança à cumplicidade” (SILVA, 2012, p. 22). O SV-PIM, nesse teatro de "marcaras", é personagem de um espetáculo real-ideal, imaginário de uma semiosfera fantástica - ou uma extensão que une os homens em escala industrial. Silva (2012, p. 21) enfatiza a essa respeito: "na era da imagem, o vivido tende para o espetáculo".

Pode-se dizer a essa altura que o SV-PIM carrega uma diversidade de possibilidades interpretativas. O símbolo, portanto, apresenta a visão do ser humano sobre esse panorama a partir de seu olhar para o entorno de si, segue um ponto de vista ecossistêmico, já que o "o olhar é o primeiro ato social" (SIMEL apud LEGROS et al, 2014), em resposta a um desejo de religação com a natureza de quem cada vez mais é apartado, mas que quer parecer estar em busca de "homeostase" (CUNHA, 2011), para inserir de novo o ser humano em seu meio, ainda que virtualmente, essa é a promessa do SV-PIM.

Para mostrar esse real ideal e simultaneamente escamotear a falácia de sucesso do PIM, o significado do símbolo sofre influência da ação dos articuladores do sistema midiático, dentre eles, as empresas - as responsáveis pela impressão do SV-PIM na embalagem dos seus produtos -; a gestora do modelo, a Suframa - a responsável pelo incremento promocional por meio das campanhas publicitárias -; a classe política - que articula a permanência do modelo PIM -; e também os criadores do símbolo, porque nele reuniram códigos culturais para em conjunto gerar semiose e servir de elo/interface produtorconsumidor através de uma personificação ambientalista.

Isso demonstra que O SV-PIM não tem recepção somente com base em signo de um objeto material, mas sim representa um sistema de signos de uma relação entre sistemas interatuantes e, por consequência, representa um ecossistema comunicacional em ação. Sua natureza complexa. Posto que através da concentração de informações, sintetiza um dado visual amplo, que, para seu efetivo entendimento, é aparelhado no imaginário do observador. Sua ação semiótica impulsiona as ações de uma mente ecológica, que perceba as interações dos sistemas como resultado de disputa por espaço. Projetamos essas relações através da Fronteiras: Revista de História | Dourados, MS | v. 19| n. 33 | p. 109 - 130 | Jan. / Jun. 2017 
perspectiva de cadeia alimentar, na qual ser humano e natureza se apoiam mutuamente para constituir esse todo orgânico. Desse contato, por meio da comunicação ecossistêmica, produzem cultura, economia e dispositivos de mediação, recursivamente.

De modo que, assim, o sistema midiático atende as demandas político-econômicas do sistema econômico, utilizando como argumento os interesses do sistema biológico, ser humano e natureza. O ser humano representado por todo o conjunto de indivíduos relacionados nessa rede é o ponto em que os sistemas se tocam. E é esse o contato representado pelo SV-PIM.

Assim percebo que nesse fenômeno da comunicação, representado pelo símbolo visual que temos tratado e que se desdobra em floresta de símbolos autossustentável, persuade o público consumidor, o trabalhador, os setores governamentais, os estados concorrentes ao modelo e, inclusive, as empresas que o reproduzem e o financiam midiaticamente, porque cria uma semiosfera midiatizada que auratiza tudo que nela está envolvido.

\section{Terra vazia}

Em analogia ao contexto histórico da Amazônia como território a ser ocupado, vazio demográfico, o entendimento desse símbolo como algo que está se movendo, que migra e que preenche espaço é bastante simbólico de uma comunicação ecossistêmica. Não é à toa que a garça se tornou símbolo. Relembro aqui o fato de ela se fazer presente nas margens de todos os rios desde a América do Norte até o Estreito de Magalhães.

Essa interface, portanto, carrega significados que remetem à relação do conjunto de empresas com a mão de obra do PIM, com o mercado consumidor, com os órgãos governamentais e com o meio ambiente em que está inserido. Tudo envolvido por um imaginário transmutado como simulacro da realidade que povoa a Amazônia e os lugares aonde o SV-PIM alcança.

\section{Espectador por procuração}

Na Amazônia existe uma "multidiversidade cultural e humana, a região (...) se enriqueceu com os afluxos humanos que para cá migraram - e isso veio a contribuir - com o abrasileiramento da Amazônia” (BENCHIMOL, 2009, p. 165). Por outro lado, hoje, com a 
espetacularização midiática do vínculo da Amazônia com o mundo, via discurso ecológico, percebe-se uma amazonificação do Brasil e do planeta, para a qual o SV-PIM tem contribuído com sua porção de irrealidade. Isso significa dizer que este sistema de signos constrói um texto cultural apoiado no discurso da dependência econômica e da preservação ambiental veiculado em propaganda institucional.

De acordo com informações o Portal do Amazonas $^{3}$, a mais recente campanha, denominada Suframa 48 anos, demandou R \$ 3,1 milhões, desse montante mais de 97\% foi destinado exclusivamente para a veiculação de propaganda. Destarte tamanho alcance e esforço de divulgação do PIM codificado em seu símbolo visual são reveladores da intenção de torná-lo cada vez mais presente no repertório imagético da população, acentuando seu caráter mediador das relações entre o ser humano, economia e as tecnologias do imaginário.

Essa propaganda, por sua vez, cria no ecossistema a reorganização constante que resulta em redundância com mais propaganda que sempre sugere a reintegração do ser humano na natureza. Dessa forma o SV-PIM se torna aquilo que Gonçalves (2010) conceitua de ecomarks: argumento publicitário das marcas no contexto da sustentabilidade ecológica. Contribui para esse ponto de vista o uso de uma ave característica da região e da cor verde que, em si, já é considerada um símbolo da Amazônia; ambas são elementos importantes de identificação do sistema biológico no âmbito do objetivo deste trabalho. Amaral Filho (2011, p. 83) reforça esse entendimento: “A Amazônia é marca da qual a cor verde é o principal elemento simbólico para induzir o consumo de produtos relacionados à floresta e à região amazônica".

Enquanto ponto rizomático - conectivo de infinitas cadeias semióticas - de uma grande rede o símbolo do PIM se inscreve em todos os produtos fabricados em Manaus com incentivos fiscais. A título de exemplo, nomeamos algumas quantidades da produção de 2014: 2,6 milhões de tablets; 12,6 milhões de televisores (LCD); 1 milhão de videogames; 2,4 milhões de reprodutores de áudio para veículos; 197,4 mil home-theaters; 107,9 milhões de CDs/DVDs; 855 mil câmeras fotográficas; 511 mil monitores para computador; 8,9 milhões de relógios de pulso; 21,2 milhões de celulares (incluindo os smartphones mais modernos da indústria mundial); 4,8 milhões de fornos de micro-ondas; 1,6 milhão de motos; 776 mil bicicletas (inclusive modelos elétricos); 173 mil computadores desktop; 1 milhão de

\footnotetext{
${ }^{3}$ Disponível em: 〈http://portaldoamazonas.com.br〉. Acesso em 2016.

Fronteiras: Revista de História | Dourados, MS | v. 19 | n. 33 | p. 109 - 130 | Jan. / Jun. 2017
} 
computadores portáteis (notebooks, ultrabooks); 2,8 milhões de reprodutores de vídeo em disco (DVD e Blu-ray); 1,2 milhão de blu-rays discs.

Números esses que totalizam a reprodutibilidade e massificação do símbolo junto à percepção do público consumidor ao volume de pelo menos 170,5 milhões de vezes. Inclusive à revelia do discurso idealizado que, por força de argumentos sedutores, os publicitários tentam estreitar a identificação entre meio ambiente, indústria e o ser humano e seu habitat. Grande parte dos grupos que se encontram inseridos na semiosfera desse ecossistema são impactados de forma sutil pelo contato com o símbolo. Uma vez que são afetados pelo SVPIM ao menos 100 mil operários das fábricas incentivadas de Manaus. Para esse grupo, $A$ garça em pleno voo (figura 1) pode representar de imediato o emprego que lhe é necessário à subsistência, portanto, um valor biológico intrínseco para quem se vê preso ao modelo que se autodenomina único e exitoso. Busca para isso causar efeitos que traduzem códigos culturais de um imaginário amazônico implícito e criteriosamente escolhido.

\section{O imaginário amazônico}

O imaginário amazônico serve de elo na realização do contato comunicativo do SVPIM com seus interlocutores. Para que isso ocorra, ele empresta das culturas locais várias características particulares desse imaginário. O público local torna-se espectador de sua própria criação.

A esse respeito Loureiro (2015, p. 95) diz que "é possível identificar-se na cultura amazônica um imaginário poetizante-estetizador governando o sistema de funções culturais, tendo como suporte material a natureza". Essa natureza fantástica é, conforme Loureiro (2015, p. 318), "natural no espírito do caboclo amazônico". Embora a produção industrial não se vincule a esse aspecto diretamente, toma emprestada essa aura, impregnando-a nos produtos do PIM.

A Amazônia é percebida por quem a contempla, como uma grandeza pura: é grande, é enorme, é terra-do-sem-fim. Sua concepção está associada a outros qualitativos: rica, incomparável, bela, misteriosa, inferno, paraíso. Algo que, embora próximo, está distante, como um outro mundo. Locus do devaneio, cujas medidas físicas desaparecem e cujos contornos se tornam sfumatos, graças a um livre pacto entre imaginário e realidade. Assimila-se sensivelmente, mais que numericamente ou cientificamente, ao meio de uma grandeza sem contornos, cujo valor reside exatamente nessa forma imaginal

Fronteiras: Revista de História | Dourados, MS | v. 19 | n. 33 |p. 109 - 130 | Jan. / Jun. 2017 
de grandeza. Ideia de grandeza que internaliza uma vaga infinidade de valores contidos nessa realidade que o imaginário transfigura. (LOUREIRO, 2015, p. 114)

Contribuem ainda para essa composição imagética, outros símbolos que formam uma imensa poluição visual capaz de hipnotizar, fomentando uma "guerra de símbolos" que se auto afirmam em um endosso mútuo. O SV-PIM expõe a natureza à implícita presença do ser humano como observador anônimo, o que é revelador da intenção de pôr a natureza como elemento mais importante; e o ser humano, simultaneamente, como seu protetor e potencial predador.

Através dessa linha de raciocínio, Paes Loureiro (2015, p. 123) enfatiza que o ser humano "da Amazônia foi construindo uma profunda forma de compreensão da vida que permitiu (até recentemente) uma peculiar unidade, um equilíbrio da vida e da cultura ao longo dos 5 milhões de km2 que integram a região". No entanto, o mesmo autor adverte:

A partir do início da década de 1970, no conjunto das crises brasileiras agravadas ou criadas durante o período da ditadura militar iniciado em 1964, que dominou vinte e um anos da história recente do Brasil, muitas mudanças ocorreram e aceleraram um processo de alterações em curso na Amazônia: os equívocos das políticas públicas para a região, decididas fora do concurso de seus líderes e das populações regionais; o conceito equivocado de "terra vazia", despovoando ideologicamente a região, por ignorar a presença dos habitantes da floresta; o desumanismo de uma atônita política de migração inter-regional e interna, no primeiro caso motivando conflitos no campo e, no segundo, transferindo a crise para a cidade; a problemática vinda de trabalhadores de outras regiões, sem adaptação cultural e sem reais oportunidades e garantias de trabalho; a implantação conflituosa de grandes projetos agropecuários, hidrelétricos e de mineração, visto que suprimem as formas de vida e trabalho anteriores e expulsam os habitantes das terras que secularmente ocuparam; a desintegração do meio do ensino de primeiro e segundo graus; a informação subordinada a grandes redes nacionais de comunicação, sem praticamente nenhuma geração de programas com base na cultura local; o desequilíbrio provocado pela migração interna do campo para a cidade; a condenação disfarçada das tribos indígenas ao extermínio; a criação de uma zona franca em Manaus e a instalação de um polo de industrias montadoras de produtos de industrias estrangeiras, sem nenhuma vinculação com as peculiaridades regionais e seus produtos (LOUREIRO, 2015, p. 123).

De tal modo, a aplicação deste imaginário amazônico ao contexto industrial gera, além de um desvirtuamento ao observador estrangeiro, também na população amazônica, conforme pensa Paes Loureiro (2015, p. 95), “(...) uma espécie de outra natureza que ele não pode mais 
preencher com os antigos signos do seu devaneio, nem povoar de mitos, nem mais se sentir imenso diante dela, da qual ele participa como "espectador interditado". Isso prova que, além de uma contrapartida legal e uma obrigatoriedade publica, o SV-PIM age para persuadir a favor do simulacro de indústria verde, do desenvolvimento econômico-social e tecnológico.

Nesse processo de convencimento, a frase que acompanha o SV-PIM, Conheça a Amazônia, remete, a nosso ver, à compreensão euclidiana de que a Amazônia continua sendo um paraíso perdido. Aliás, a obra de Cunha, no seu conjunto, constitui importante documento sobre a paisagem amazônica imaginada como um lugar à espera de descobrimento. Escuda-se dessa maneira por traz de uma imagem mental estonteante. Destacamos ainda esta passagem emblemática desse autor:

Todos nos desde muito cedo gizamos um Amazonas ideal, mercê das páginas singularmente líricas dos não sei quantos viajantes que desde Humboldt até hoje contemplaram a hylae prodigiosa, com um espanto quase religioso (...) ao defrontarmos o Amazonas real, vemo-lo inferior à imagem subjetiva há longo tempo prefigurada (CUNHA, 2003, p. 33).

Hoje vemos o ser humano amazônico preso à perspectiva econômica do PIM, em um cenário que não lhe favorece. No entanto, a ele se agarra com todas as suas forças, como se percebe pelos movimentos políticos no sentido de perpetuar esse modelo econômico, que no atual contexto, oculta a riqueza da Amazônia e leva a população sob a sua influência a imaginar que se encontra em um beco sem saída, assim como os seringais afetavam os trabalhadores da borracha na visão euclidiana:

É a imagem monstruosa e expressiva da sociedade torturada que moureja naquelas paragens. O cearense aventuroso ali chega numa desapoderada ansiedade de fortuna; e depois de uma breve aprendizagem em que passa de brabo a manso, consoante a gíria dos seringais (o que significa o passar das miragens que o estonteavam para a apatia de um vencido ante a realidade inexorável) - ergue a cabana de paxiuba à ourela mal destoucada de um igarapé pinturesco, ou mais para o centro numa clareira que a mata ameaçadora costringi, e longe do barracão senhoril, onde o seringueiro opulento estadeia o parasitismo farto, pressente que nunca mais se livrara da estrada que o enlaça, e que vai pisar durante a vida inteira, indo e vindo, a girar estonteadamente no monstruoso círculo vicioso de sua faina fatigante e estéril (CUNHA, 2003, p. 338).

Diferentemente do seringueiro que, após o contato com a exploração, sonhava com a liberdade, o trabalhador do PIM anseia tão somente pela continuidade desse modelo, seduzido 
pelo imaginário de sucesso que se criou em torno dele; já que do ponto de vista do colonizador, o Amazonas, desde os tempos antigos, recebe nomeações e descrições prestigiosas, como de País das Amazonas, homenagem às índias guerreiras que a expedição do primeiro navegador a singrá-lo, o espanhol Francisco Orellana, teria encontrado - e com elas guerreado - na hoje foz do Rio Nhamundá, no Baixo Amazonas. Pode-se dizer que a invenção da Amazônia nasce, por meio desse episódio, inserido no imaginário universal, em vista do transplante da história das amazonas, de origem indo-europeia, para esse Novo Mundo coberto de águas e florestas colossais e habitado por gentes com modos de pensar, agir e viver tão diferentes daquelas que estavam chegando por aqui. Não seria de se estranhar que até os dias de hoje parte significativa da população do mundo ainda imagine o Amazonas - e na sua extensão denominativa a Amazônia - por meio das cenas e cenários da literatura, dos relatos de viajantes e aventureiros, dos filmes, da pintura etc. Por isso, o PIM com suas fábricas de produtos de ponta toma partido desse imaginário atribuindo-o a si mesmo, por meio da propaganda e publicidade, o papel de agente civilizador, assim como pareciam ser os seringais que transformariam Manaus na Paris da selva. No conjunto das suas intenções veladas é que o SV-PIM almeja enquanto simulacro desse imaginário disseminado hoje por meios muitos mais poderosos.

Há, no entanto, uma Amazônia real com legado ancestral que contrasta com a Amazônia espetacularizada pelas campanhas da Suframa. É sobre ela que Benchimol nos fala:

O conhecer, o saber, o viver e o fazer na Amazônia colonial foi um processo predominantemente indígena. Os ameríndios que iniciaram essa ocupação e os seus descendentes caboclos (do tupi caa-boc, tirado ou precedente do mato, segundo Teodoro Sampaio) desenvolveram as suas matrizes e os seus valores, baseado no íntimo contato com o ambiente físico e biológico. O seu ciclo de vida se adaptava as peculiaridades regionais, dela retirando os recursos materiais de subsistência e as fontes de inspiração do seu imaginário de mitos, lendas e crenças (BENCHIMOL, 2009, p. 25).

$\mathrm{O}$ mesmo autor se refere aos estereótipos que se criaram sobre a região mais recentemente, em razão dos mais variados interesses, mas o principal deles continua sendo o econômico, com foco na questão ecológica, que ganhou força a partir da década de 1990 com os resultados de pesquisa dando conta que a poluição gerada pelos seres humanos está "matando" o planeta. O mais grave segundo Benchimol (2009, p. 508) é que esses estereótipos escondem os verdadeiros problemas e possíveis soluções para a região, porque 
são frutos de ideias que continuam ignorando a Inteligência das populações amazônicas. Assim salienta Benchimol:

\begin{abstract}
A preocupação ecológica e ambiental, que se apossou da mente dos líderes dos povos industrializados e desenvolvidos, fez da Amazônia um símbolo de toda a preocupação mundial sobre o destino do nosso planeta. Mais do que isso. Em muitos países, lideranças políticas e proféticas premonições paracientíficas criaram a imagem e o estereotipo de que pesa sobre a Amazônia a responsabilidade de manter integro os seus ecossistemas silvestres, para que o restante da humanidade possa usufruir e manter os seus atuais padrões e tecnologias poluidoras e degradantes dos seus sistemas de produção. A floresta amazônica, assim, para essa corrente de ecologia fundamentalista, deverá ser mantida e preservada como um santuário, para poder exercer sua função de sumidouro do dióxido de carbono, produzido pelos países do hemisfério norte, manter a temperatura e o clima globais em equilíbrio e sustentar, com sua imensa bio-diversidade, as necessidades genéticas da população futura (...). Este novo e falso conceito e percepção unilateral e radical do problema já tem feito sentir os seus efeitos e impactos sobre a região sob diferentes formas políticas (BENCHIMOL, 2009, p. 508).
\end{abstract}

Desses episódios fica a certeza de que a Amazônia é um símbolo mundial e o SV-PIM deseja representá-lo em meio a um processo sinérgico de marcas. Parafraseando Benchimol, se a Amazônia é um símbolo mundial eivado de estereótipos, as ideias carreadas pelo SVPIM também podem gerar interpretações falsas sobre as relações do PIM com a Amazônia. Os estereótipos podem gerar conclusões de que as populações autóctones da Amazônia, principalmente caboclos e índios que teriam migrado para cidades em busca de emprego, são hoje a grande ameaça para permanência da floresta em pé, caso as fábricas do PIM percam os incentivos fiscais e fechem as suas portas. Os termos da importante e necessária causa ecológica deixam de ser tão importante e tão necessário quando manipuladas por interesse puramente econômico.

Outro fato que indica o insucesso do que se planejou para o modelo é que ele não se transformou em real soberania para a Amazônia. Sem que isso se evidencie num nacionalismo de retórica militarista, é possível dizer que visões e determinações estrangeiras impuseram - e ainda impõem - limites para a ação do ser humano amazônico sobre o solo que pisa, porque, como aqui já apontamos, o capital investido no PIM é, em grande parte, de origem transnacional. Esse é mais um dado oculto a partir da narrativa mítica do PIM, agora sob a bandeira do apelo economicamente sustentável, ecologicamente equilibrado e socialmente justo. É o ente mítico que reforça uma barreira imaginaria entre os limites urbanos e a floresta 
que o constringe. Advém daí o imaginário que mantém sob controle tais interesses, os quais vão desde a soberania relativa ao desagravo do capital estrangeiro. Põe-se, assim, em colapso o antigo discurso militarista de posse, e agora se manifesta um novo discurso com enfoque na “abertura de portos", para viabilizar a comunicação e a integração da Amazônia às demais regiões do País. O novo discurso reúne "sob as asas da garça do SV-PIM" diversas empresas multinacionais conhecidas mundialmente com suas respectivas marcas em justaposição ao símbolo do PIM. Esses símbolos também afetam esse ecossistema comunicacional, já que eles introduzem um imaginário imperativo de globalização do local, que se manifesta no slogan Amazônia para o mundo conhecer.

Seguindo o método de descrição desse diálogo econômico transmutado para a comunicação, busamos conhecer os modos de leitura do SV-PIM por quem os produz e os interpreta: criador, gestor, consumidor e trabalhador. Adotamos essa postura porque percebemos a necessidade de entender que esse fenômeno articula a complexidade. E, por isso mesmo, os pontos ocultos que se escondem atrás do que é mostrado podem ser revelados por esse mesmo princípio de entrelaçamento complexo. Dois questionamentos, assim, podem ser feitos: o que de fato se interpreta pela recepção do símbolo? E se essa interpretação realmente corresponde à realidade? Ou tudo isso é apenas uma crença produzida pelo diálogo que tratamos. Ainda que se resumam a crenças fantasiosas, elas também possuem poder de persuadir. Sobre este tipo de comunicação Morin (2011, p. 21) faz o seguinte comentário: “As ideias, as crenças, os símbolos e os mitos são não só potencias e valores cognitivos, mas também forças de ligação e coesão sociais”. E acrescenta:

Se podemos chamar "propaganda" um conjunto de princípios, regras e instruções que comandam/controlam operações cognitivas, podemos dizer que as atividades cognitivas do ser humano emergem de inter-retroações dialógicas entre um poligrama comportando instâncias complementares, concorrentes e antagônicas. A percepção das formas e das cores e a identificação dos objetos e dos seres obedecem a conjunção de esquemas inatos e de esquemas culturais de reconhecimento (MORIN, 2011, p. 22).

Portanto, como já afirmamos no decorrer do texto, essa transmissão cultural midiatizada tem o poder de introduzir o SV-PIM no imaginário amazônico, pois é ele próprio um simulacro desse imaginário. Para isso, empregam-se as tecnologias do imaginário que simulam a relação dele com o contexto do ecossistema midiático, econômico e biológico. Outro meio de representar esse pensamento segue registrado no diagrama abaixo (figura 2): 
Figura 02: Ecossistema comunicativo do Polo industrial de Manaus

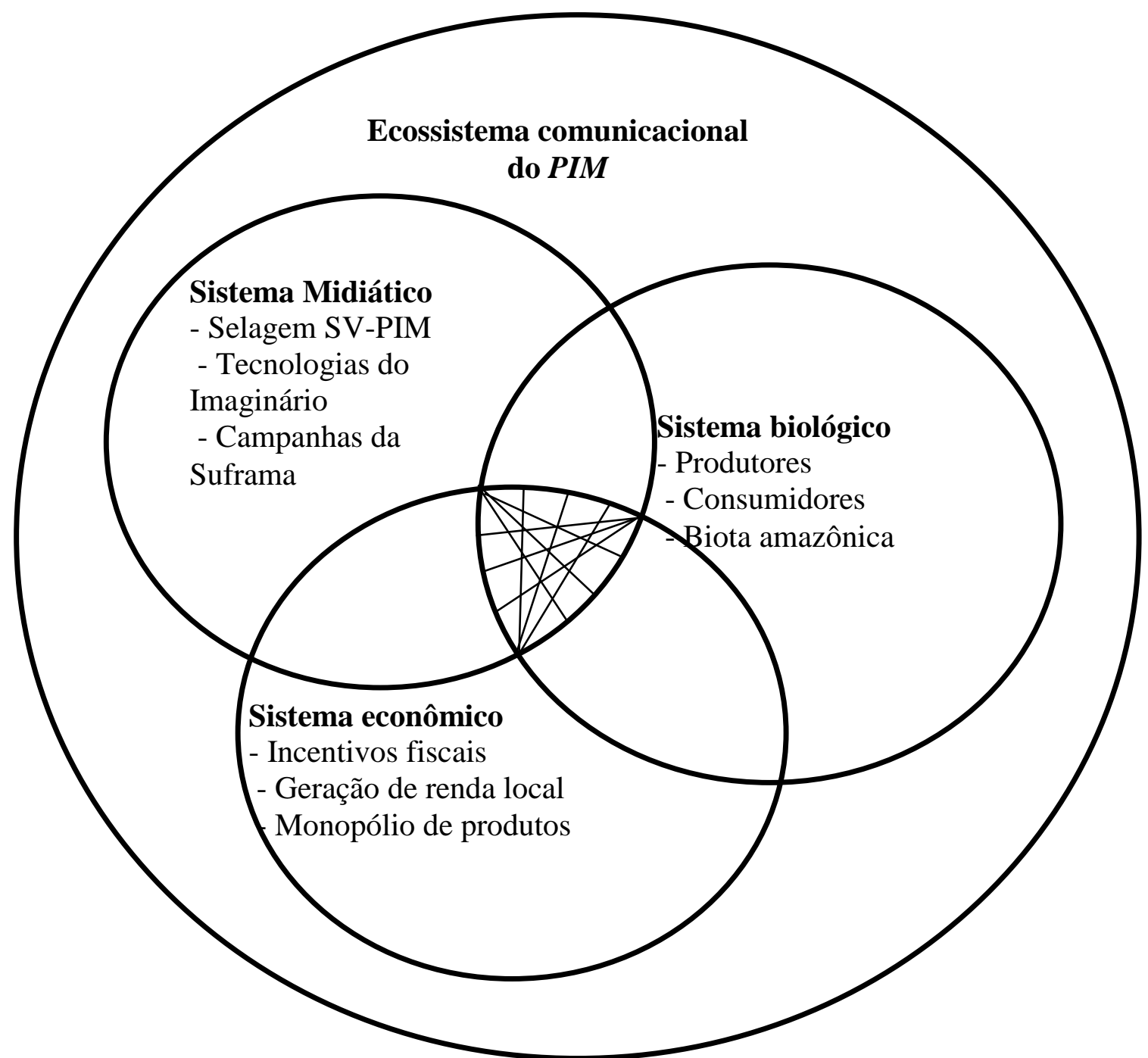

No ecossistema em tela (figura 2), o processo de conexão usa como estratégia dar ênfase aos valores que se agregam ao SV-PIM, tais como; valor econômico, valor social, valor cultural, valor ambiental. Além de servir como reforço ao consumo, essa estratégia emite mensagem de posse a partir da Inclusão do SV-PIM nas embalagens, caracterizada como uma reprodutibilidade técnica em escala industrial. A propagação do SV-PIM em larga escala, como um "bombardeio" de mensagens portadoras de fragmentos do imaginário amazônico, cria outro imaginário: o de sucesso do modelo em questão enquanto projeto de desenvolvimento, preservação da biodiversidade e "santuário silvestre" (BENCHIMOL, 2009, p. 508).

Vimos que as campanhas publicitárias aqui abordadas, enquanto tecnologias do imaginário, são intensificadas quando fatos ocorridos na política ou planejamentos 
econômicos afetam o PIM. Elas surgem então como uma resposta (feedback) que objetiva persuadir e gerar a partir de seus (inputs) outras respostas (outputs) pelos demais sistemas. Assim, o sistema biológico é também acionado objetivando a persuasão que se concentra nos argumentos da preservação e economia em harmonia. Toda alteração no quadro antropológico do sistema biológico, que envolvam a cultura, os modos de subsistências, a possibilidade de diminuição de arrecadação ou de emprego, surte efeito nos argumentos do sistema midiático. Após a ação de uma campanha, há inegável envolvimento emocional quanto à importância da prorrogação, sentimento que influencia decisões políticas que, em certo sentido, são também afetados pela opinião pública.

Essas campanhas, portanto, são resultados de um conjunto de sinais das reações e contrarreações dos contatos entre as fronteiras sígnicas, as quais geram novos contatos e novas reações e contrarreações. É nesse processo contínuo de resignificação comunicacional que o modelo persiste sem mudar a sua estrutura econômica e política de origem, porque sempre recupera condições ambientais - ou ambiente comunicacional - para se reorganizar ante as reações que tendem a levá-lo ao caos.

Vemos ainda nessas ocorrências mensagens emitidas pela interatividade entre os sistemas. Pois o contato dessas fronteiras faz com que haja reações emitindo sinais desse encontro; esses sinais ou signos constituem uma linguagem heterogênea a ser traduzida, e o SV-PIM é responsável por este efeito tradutor comunicativo.

A mediação desses toques só se mostra pelo ser humano, pela cognição inteligente cujo conjunto do modo de pensar semelhante forma o imaginário. Como já foi afirmado, existe no cenário social local a necessidade de identificação com o símbolo do PIM, uma vez que para os integrantes do ecossistema comunicacional, ele possui importância biológica, porque representa para o ser humano da Amazônia Ocidental um meio de manutenção econômica que lhe traz o sustento. Inexiste, para ele, a perspectiva de meios diferentes senão os de industrialização. E a possibilidade de fim do ciclo ZFM/ PIM - mais um entre outros - é um temor presente, de modo que esse ser humano também é envolto na cultura do PIM à medida que seu símbolo, seduz pelo imaginário. Afinal, como explica Morin (2011, p. 21), "Desde o seu nascimento o ser humano conhece não só por si, para si, em função de si, mas também, pela sua família, pela sua tribo, pela sua cultura, pela sua sociedade, para elas em função delas". 
Essas relações, que se efetivam e se desenvolvem por meio da comunicação ecossistêmica, mantêm a interlocução de seus elementos constituintes. O diálogo é o laço e o SV-PIM é o que o materializa, tornando-o visível enquanto nó de uma rede comunicacional complexa. De todos esses contatos ecossistêmicos até aqui revelados, o que se nota é que o principal sinal repercutido por essa abordagem foi o êxito em obter-se a prorrogação do polo industrial de Manaus até 2073, não obstante seu aspecto de insustentabilidade econômica e social para a região.

\section{Para finalizar}

Percebemos, conforme o que aqui foi exposto, que o SV-PIM exerce papel relevante no ecossistema PIM, pois, além de veículo imediato desta mensagem, também contribui para que a integração entre ser humano e natureza se firme no imaginário dos seus produtores/consumidores. Por intermédio do SV-PIM, criou-se em torno do PIM, em um período recente, um imaginário que espetaculariza sua atuação na Amazônia. Portanto, o SVPIM é a síntese visual deste entendimento: o de que a espetacularização busca acentuar sua presença como interface simbólica, e para isso usa códigos culturais impressos em seus aspectos estéticos com o objetivo de ratificar a possível relação preservacionista do modelo, sua possível condição de única opção de economia para a população amazônica, e a sua possível contribuição econômica, financeira e ambiental para todo o País.

Apoiando-se em aspectos do imaginário amazônico, o PIM projeta uma ideal relação entre indústria e natureza e desestimula a busca de outras opções de usufruto das riquezas regionais em consonância com as peculiaridades do seu ecossistema. Ao mesmo tempo, essa relação idealizada oculta, deliberadamente, demais interesses que certamente também perturbam esse ecossistema comunicacional, dentre eles, os das empresas e do próprio governo arrecadador, os quais servem de escudo para ações opositoras dos estados contrários às vantagens econômicas concedidas ao PIM.

Está claro que, com os suportes midiáticos apresentados, o SV-PIM possui extenso alcance e importância para o entendimento do diálogo entre os sistemas que aqui consideramos. Este fenômeno da comunicação descreve um diálogo entre economia, ser humano e natureza, uma comunicação ecossistêmica, na qual o SV-PIM é dispositivo do sistema midiático que, motivado por aspectos legais e pelo interesse econômico dos órgãos 
governamentais das empresas-marcas, concentram nele um valor imaterial, imaginário. Esse imaginário é a representação da cultura amazônica vendida a reboque nos produtos do PIM. Enfim, esse é o trajeto de um crônico insucesso de política de desenvolvimento econômico regional que se traveste pela rede comunicacional que lhe suporta no desenrolar das mudanças socioculturais do Amazonas, da Amazônia, do Brasil e do mundo, como sucesso em pleno voo.

\section{Referências}

ARNHEIM, Rudolf. Arte e percepção visual: uma psicologia da visão criadora. São Paulo: Pioneira, 2006.

BENCHIMOL, Samuel. Amazônia - formação social e cultural. 3. ed. Manaus: Valer, 2009.

BOTELHO, Antônio José. Redesenhando o projeto: Zona Franca de Manaus. Manaus: Valer, 2006.

CONSELHO NACIONAL DE AUTORREGULAMENTAÇÃO PUBLICITÁRIA. Julgamento da campanha "ZONA FRANCA DE MANAUS - TECNOLOGIA, DESENVOLVIMENTO, SUSTENTABILIDADE” 2012. Disponível em: <http://www.conar.org.br >. Acesso em 27 maio 2016.

CUNHA, Euclides da. Amazônia - Um paraíso perdido. Manaus: Editora Valer/ Governo do Estado do Amazonas/ Editora da Universidade Federal do Amazonas, 2003.

DEBORD, Guy. A Sociedade do Espetáculo. Rio de Janeiro: Contraponto, 1997.

DONDIS, Donis A. Sintaxe da linguagem visual. Tradução Jeferson Luiz Camargo. 3 ed. São Paulo: Martins Fontes, 2007.

DURAND, Gilbert. Campos do imaginário. Lisboa: Instituto Piaget, 1996.

FLUSSER, Vilém. Filosofia da caixa preta. São Paulo: Hucitec, 1985.

GONÇALVES, Johane dos Santos. Ecomarks: A construção do argumento publicitário das marcas no contexto da sustentabilidade. 83 f. Dissertação (Mestrado em Ciências da Comunicação). Universidade Federal do Amazonas, Manaus, 2010.

INSTITUTO NACIONAL DE PESQUISAS ESPACIAIS. Desmatamento na Amazônia. Disponível em: <http://www.inpe.br>. Acesso em 18 jul. 2016.

LAREDO, José. PIM - Polo Industrial de Manaus: Performance e prognóstico. Manaus: Ziló, 2013. 
LEGROS, Patrick et al. Sociologia do imaginário: Frederic Monneyron, Jean- Bruno Renard,Patrick Legros e Patrick Tacussel. Tradução de Eduardo Portanova Barros. 2. ed. Porto Alegre: Sulina, 2014.

LEMOS, André. Cibercultura: Tecnologia e vida social na cultura contemporânea. Porto Alegre: Sulina, 2013.

LOUREIRO, João Jesus Paes. Cultura Amazônica - uma poética do imaginário. 5. ed. Manaus: Valer, 2015.

MACHADO, Irene. Semiótica da cultura e semiosfera: Apontamentos para a historicidade das ideias precursoras da semiosfera. São Paulo: Annablume, 2007.

MAFFESOLI, Michel. O tempo das tribos: o declínio do individualismo nas sociedades de massas. Tradução Maria de Lourdes Menezes; Apresentação e revisão técnica Luiz Felipe Baeta Neves. 5. ed. Rio de Janeiro: Forense, 2014.

MONTEIRO, Gilson Vieira. Por uma pesquisa amazônida em Comunicação: provocações para novos olhares. Belém: FADESP, 2011.

MORIN, Edgar. Introdução ao pensamento complexo. Porto Alegre: Editora Sulina, 2007.

MORIN, Edgar. O método 4: As ideias: habitat, vida, costumes, organização. Tradução Juremir Machado da Silva. 6. Ed. Porto Alegre: Sulina, 2011.

MORIN, Edgar. O método II: a vida da vida. Tradução de Marina Lobo. Porto Alegre: Sulina, 2011.

PEREIRA, Deusamir. Amazônia (in)sustentável: Zona Franca de Manaus - Estudo e análise. Manaus: Valer, 2006.

PEREIRA, Mirna Feitoza. Estudos e perspectivas dos ecossistemas na comunicação. Manaus: EdUA, 2012.

PORTAL DA AMAZÔNIA. As origens do selo da zona franca de Manaus. Disponível em: <http://portalamazonia.com>. Acesso em 19 out. 2014.

SANTAELLA, Lucia. Matrizes da linguagem e pensamento: sonora, visual, verbal Aplicações na hipermídia. 3 ed. São Paulo: Iluminuras/Fapesp, 2005.

SARTRE, Jean Paul. L' ímaginare. 1971 (1940).

SILVA, Juremir Machado. As tecnologias do imaginário. 3 ed. Porto Alegre: Sulina, 2012.

SUPERINTENDÊNCIA DA ZONA FRANCA DE MANAUS. A história da ZFM. Disponível em: 〈http://www.suframa.gov.br/zfm> Acesso em: 14 jun. 2016. 
SUPERINTENDENNCIA DA ZONA FRANCA DE MANAUS. O que é o projeto ZFM. Disponível em: 〈http://www.suframa.gov.br/zfm_.cfm> Acesso em: 14 jun. 2016.

Recebido em: 03/03/2017 Aprovado em: 09/06/2017 